\title{
PSICOPEDAGOGIA INSTITUCIONAL: POSSIBILIDADES E LIMITES NO ENSINO SUPERIOR
}

\author{
Gleicione Apa Dias Bagne de SOUZA ${ }^{1}$
}

\begin{abstract}
${ }^{1}$ Reitora e Pró-reitora de Graduação e Assuntos Acadêmicos da Universidade Vale do Rio VerdeUninCor
\end{abstract}

\section{Recebido em: 30/10/2013 - Aprovado em: 18/12/2013 - Disponibilizado em: 15/01/2014}

RESUMO: Este artigo discute alguns aspectos que devem nortear o ensino superior. Diagnostica alguns problemas e promove ao professor possibilidades de um olhar diferenciado aos alunos e ao seu fazer pedagógico. É mostrada a importância da atuação de um psicopedagogo na instituição, como um profissional atuante, capaz de coordenar reflexões da atuação do professor e dos demais funcionários em relação ao currículo, ao aluno, à instituição e à sociedade.

PALAVRAS-CHAVE: Psicopedagogia. Ensino Superior. Educação. Professor.

\begin{abstract}
ABSTRAT:This article discusses some aspects that must orientate the Higher Education. It iagnoses some problems and promotes to the teacher, possibilities of a differentiated look of the students as well his pedagogic. It is shown the importance of the Psicopedagogo performance in an Institution, as a professional that actuates, capable to coordinate reflections about the teacher's performance and of the other employees in relation to the Curriculum, to the student, to the institution and the society.
\end{abstract}

KEYWORDS: Educational Psychology . Higher Education. Education . Teacher.

\section{1- INTRODUÇÃO}

Com os parâmetros de Avaliação da Educação Superior, há exigência na concepção de uma educação aos egressos de excelência, na qual as habilidades e competências para a formação do profissional nas diversas áreas do conhecimento devem atender e contemplar as Diretrizes Curriculares Nacionais e o Catálogo de Curso Superior de Tecnologia.

Ao mesmo tempo, a instituição deve atender também aos anseios da sociedade do conhecimento, do mercado de trabalho e da qualidade definida pelo Ministério da Educação, através do ENADE e do instrumento de avaliação de cursos superiores.

Sabe-se que muitos alunos chegam a IES com determinadas dificuldades relacionadas a questões relativas aos conhecimentos construídos na Educação Básica. Há também outros fatores que limitam a aprendizagem do aluno do Ensino Superior e que a psicopedagogia pode contribuir em relação à modalidade de aprender e ensinar, 
incentivando a autonomia e a subjetividade do aprendiz que busca construir seu conhecimento articulando á sua prática profissional.

O Ensino Superior deve contemplar a reflexão no processo de ensinar, principalmente no que se refere à capacidade de pensar do adulto, levando em consideração suas aptidões, frente às habilidades e competências que a futura profissão exigirá.

Assim, a função do psicopedagogo no Ensino Superior deve ser:

[...] prevenir e intervir nos processos cognitivos, emocionais, sociais, culturais, e pedagógicos do acadêmico, oferecendo ao mesmo suporte, atuando sobre os múltiplos fatores que possam interferir, no seu desenvolvimento integral, nas questões ligadas a aprendizagem. Como também oferecer subsídios para que os docentes trabalhem com os acadêmicos em sala de aula, assumindo transformações necessárias, e buscando sempre soluções apropriadas às demandas emergentes.(FUNDASUL, 2015, p.1).

Diante do exposto, conhecer os alunos, suas características, potencialidades, suas formas de construir o conhecimento, seu desenvolvimento acadêmico, social e pessoal é uma forma também de prevenir dificuldades, defasagens e evasão.

\section{2- POSSIBILIDADES E LIMITES DA PSICOPEDAGOGIA NO ENSINO SUPERIOR}

A escola universitária é uma instituição aberta que possui uma organização, uma história e características próprias e por isso está em interação com outros sistemas. Ela é um espaço vivo, em cujo interior mudanças ocorrem, seja na transformação de seus educadores, na de seus alunos, da coordenação, da reitoria, da secretaria ou na equipe de apoio. Essas mudanças que vão ocorrendo no interior da instituição caracteriza o momento atual da conjuntura político-pedagógico e, dessa forma, sofre influências tanto do exterior como do interior de uma sociedade e, muitas vezes, essas mudanças desestabilizam o sistema. Para isso, há necessidade de se estabelecer objetivos que irão permear a escola como sistematizadora do saber; não mais essencialmente transmissora, mas administradora dos conhecimentos advindos do contexto social e compilando saberes significativos para a diversidade e a complexidade de uma clientela escolar diversa, complexa e que necessita compreender o mundo em transição.

Cabe aos professores universitários inserir na prática pedagógica os quatro pilares da Educação, segundo a UNESCO - Comissão Internacional sobre Educação para o século XXI, proporcionando aos alunos o "aprender a conhecer" para adquirir ferramentas básicas 
para conhecer os fatos, conceitos e princípios; o "aprender a ser" pelo qual se desenvolve a personalidade e identidade do aluno; o "aprender a viver juntos": saber participar e cooperar com os outros os valores, atitudes e normas e ainda, o "aprender a fazer" isto é, adquirir uma profissão. Esse pilar é um dos pontos fortes que deve ter realmente assegurado aos alunos, pois ele já fez sua escolha profissional, mas não se pode enxergá-lo somente por frestas. Há necessidade de trabalhar esses pilares como um todo não fragmentar.

Como educador, é necessário oferecer aos alunos uma educação que possa atender às exigências do mercado de trabalho atual, não só na formação técnica, mas na formação integral do ser humano. Para isso deve-se ter um olhar diferenciado para enxergar a diversidade, complexidade e singularidade desse aluno que está sendo trabalhado, sendo acolhedores, tolerantes, amorosos e fundamentalmente mais responsáveis e comprometidos, pois se sabe hoje que a integridade, autonomia e criatividade de uma nação dependem, em grande parte, da educação oferecida.

É de responsabilidade da Coordenação Pedagógica subsidiar esse professor, preparando-o para uma mudança de postura significativa, pois antes mesmo de inserir os quatro pilares na educação, esse professor deverá estar preparado para lidar com as dificuldades de aprendizagem de seus alunos.
Muitas vezes essa dificuldade de aprendizagem dos alunos é vista pelo professor como desinteresse do discente, falta de compromisso, falta de tempo para rever os conteúdos que foram ministrados ou até considerando o aluno como mais um a procurar apenas o diploma.

Será que o aluno universitário não tem problemas com a construção do saber? Será que a dificuldade de aprendizagem só ocorre com os alunos da Educação Básica?

Sabe-se que muitos são os fatores que influenciam na construção dos conhecimentos em sala de aula e no processo educacional como um todo: os herdados da Educação Básica, os conflitos internos e externos de cada um e, em se tratando de instituições privadas de ensino superior, a problemática questão financeira e a divisão entre os estudos e o emprego.

O psicopedagogo trabalha com a construção da aprendizagem, logo será um profissional que dará suporte ao docente, uma vez que o código de ética elaborado pelo Conselho Nacional do biênio 91/92 e reformulado pelo Conselho Nacional e Nato do biênio 95/96 aponta fundamentos que norteiam todas as ações. Conforme o próprio código a psicopedagogia no contexto institucional:

Artigo $1^{\circ}$ : A Psicopedagogia é um campo
de atuação em Educação e Saúde que lida
com o processo de aprendizagem humana;
seus padrões normais e patológicos,
considerando a influência do meio -
família, escola e sociedade - no seu 
desenvolvimento, utilizando procedimentos próprios da Psicopedagogia. Parágrafo Único: A intervenção psicopedagógica é sempre da ordem do conhecimento relacionado com o processo de aprendizagem. (ABPP, 1996, p.1).

Sabe-se que a maioria dos professores universitários não possui formação em licenciaturas e sim em áreas diferentes: Ciências Exatas e da Terra; Ciências Biológicas; Engenharias; Ciências da Saúde; Ciências Agrárias e outras. Para esses profissionais que fazem a opção pela docência, fica muito difícil lidar com as questões de metodológicas de ensino, didática e das dificuldades de aprendizagem de seus alunos. Até certo ponto, se propõe no dia-a-dia o ato de ensinar, não enxergando a outra vertente que é $\mathrm{o}$ ato de aprender, neste contexto que entra a atuação do psicopedagogo.

Este poderá ser um profissional atuante na universidade, orientando na instrumentalização do professor, coordenador e outros profissionais da área sobre práticas e reflexões diante de novas formas de aprender.

A psicopedagogia estuda o ato de aprender e ensinar, levando sempre em conta as realidades interna e externa da aprendizagem, tomadas em conjunto. E, mais, procurando estudar a construção do conhecimento em toda a sua complexidade, procurando colocar em pé de igualdade os aspectos cognitivos, afetivos e sociais que lhe estão implícitos. (BOSSA apud NEVES, 2000, p. 24).

$$
\text { Poderá também ajudar }
$$

na

reprogramação curricular, na reintegração do aluno no processo, na reconstrução conceitual e em muitos outros fatores. Como diz Bossa:

\begin{abstract}
Pensar a escola à luz da Psicopedagogia implica nos debruçarmos especialmente sobre a formação do professor. Pode-se dizer, por conseguinte, que uma das tarefas mais importantes na ação psicopedagógica preventiva é encontrar novas modalidades para tornar essa formação mais eficiente. Sabe-se que as profissões escolhidas atendendo a profundos desejos inconscientes, e que não se questiona e nem se leva em conta as motivações dessa escolha ao longo da formação do professor. (2000, p.94).
\end{abstract}

\section{Segundo MENDES:}

\begin{abstract}
A psicopedagogia entende que o professor deve criar condições para que os processos cognitivos se desenvolvam, pois o ensino só é efetivo quando nos propicia o caminho do desenvolvimento. Por esta razão é que defendemos uma proposta de intervenção, cujo foco é a modalidade de circulação do conhecimento; dito de outra forma, seria olhar a maneira como os atores educativos compartilham seu conhecimento, seu saber! (2000, p.33).
\end{abstract}

De acordo com as ideias de Bossa e Mendes, a Psicopedagogia se ocupa em analisar, reconstruir processos, definir papéis, valorizar novos conhecimentos, novas formas de aprender, novas formas de avaliar o conhecimento, investigar e realizar novas propostas para a formação do educador. Esse educador universitário que tem cada dia mais investido em sua formação caminhando em busca de conquistas acadêmicas, tem adquirido novos e importantes conhecimentos em sua área 
de atuação, mas um dos conhecimentos mais importantes na formação dos alunos tem ficado a desejar: a afetividade. Busca-se cada dia mais a aquisição de novos saberes e esquece-se que o saber só tem significado para os alunos se acolhido com uma parcela de amizade, respeito, empatia, doação e envolvimento. Esse é um dos interesses da Psicopedagogia: refletir sobre essas questões, buscando dar a sua contribuição, no sentido de prevenir futuros problemas de aprendizagem.

Dessa forma, qual será o ponto de partida para o trabalho psicopedagógico na Universidade?

Acredita-se que o ponto de partida está na reflexão individual e grupal sobre as próprias aprendizagens. O professor deve fazer a autoavaliação de sua postura como educador, de sua forma de atuação, da metodologia utilizada, dos objetivos de sua disciplina, da forma de avaliar os alunos e do conteúdo programático. Através dessa auto-avaliação o educador terá uma visão clara de onde e como deverá permear sua prática pedagógica.

A Universidade deverá também passar pelo mesmo processo: "o que tem reproduzido como Universidade?", “Tem valorizado seus profissionais?", “Tem oferecido ambiente tranquilo para uma boa atuação do profissional?", “Tem oferecido suporte metodológico e suporte técnico?", "Sua prática tem sido coerente com sua exigência?", "Como é o relacionamento Reitoria/Pró-reitoria/
Diretores/ Coordenadores e Professores?". Quanto mais a Universidade fizer a sua autoavaliação e a dos educadores, quanto menos mantiver estereótipos e ambiguidades, mais ela livrará o aluno de ser o próprio responsável pelo fracasso ou abandono da instituição.

Segundo ASSMANN:

\begin{abstract}
Precisamos de muitas frentes de luta pela melhoria da educação. Mas não se pode ir contornando eternamente a evidência de que a questão da qualidade na educação passa centralmente pelo viés pedagógico. Esta é a minha tese de fundo. Pergunto-me se os/as educadores não perdem pontos em suas lutas reivindicatórias quando não explicitam adequadamente esta opção clara pró-reencantamento da educação no plano pedagógico (1998, p.23).
\end{abstract}

A educação universitária necessita de educadores entusiasmados com seu papel na sociedade, com educadores motivados a fazer da Universidade um lugar de sedução do conhecimento, educadores que favoreçam processos de interação, formam seres humanos criativos capazes de intervir na sociedade e capazes de sonhar.

\section{CONSIDERAÇÕES FINAIS}

$\mathrm{O}$ que se pretende com as reflexões anteriores não é contratar mais um profissional permanente na universidade, mas um profissional que poderá prestar assessorias, fazer um diagnóstico e intervenções periódicas e oferecer capacitações aos profissionais da instituição. Necessita-se de um profissional que 
possa realizar um trabalho, introduzindo novas

e diferentes formar de trabalhar, ressignificando

a educação e o sentido da mesma, procurando acima de tudo resgatar as dificuldades do aluno e professores na difícil, mas saborosa arte de educar. "A arte suprema do mestre consiste em despertar o gozo da expressão criativa e do conhecimento." Albert Einstein

\section{REFERÊNCIAS BIBLIOGRÁFICAS}

ASSMANN, Hugo. Reencantar a Educação Rumo à sociedade aprendente. 2 ed. Petrópolis: Vozes, 1998.

BOSSA, Nádia. A Psicopedagogia no Brasil: contribuições a partir da prática. 2.

ed. Porto Alegre: Artes Médicas Sul, 2000.

CONSELHO NACIONAL - Biênio 95/96. Código de Ética da ABPp.

\section{FUNDASUL. Psicopedagogia no Ensino}

Superior. Disponível em:

$<$ http://www.fundasul.br/159/servicospsicologia-e-psicopedagogia-psicopedagogiano-ensino-superior/>. Acessado em: 02 de abril de 2014.

Revista da Associação Brasileira de Psicopedagogia. "Psicopedagogia

Institucional- uma proposta de intervenção". Mônica Hoehne Mendes. Volume 19. nº51 2000 SALESIANAS 